\title{
A Novel Mechanism for Xenia?
}

\author{
Yongsheng Liu ${ }^{1,2}$ \\ Department of Horticulture, Henan Institute of Science and Technology, \\ Xinxiang, 453003, China
}

Additional index words. xenia, metaxenia, Darwin's Pangenesis, mRNA action hypothesis

Abstract. Although xenia is widespread in plants and has applications in genetics, physiology, breeding and production, its mechanism remains poorly understood. Here I briefly discuss several previous explanations for xenia, and propose an mRNA action hypothesis, which is consistent with Darwin's Pangenesis.

Xenia (including metaxenia) is described as the direct or immediate pollen effect on the size, shape, color, developmental timing, and chemical composition of seeds and fruits (Denney, 1992). It has been proven that xenia is widespread and common in plants and has applications not only in plant genetics and physiology, but also in plant breeding and crop production. Now the practical importance of xenia has been realized by many plant growers and horticulturists, but its mechanism remains poorly understood.

As early as 1868 , Darwin devoted six pages to "the direct or immediate action of the male element on the mother form" (now we call xenia) in his book The Variation and described it as being "of the highest theoretical importance." To explain xenia, graft hybridization, reversion, prepotency, telegony, regeneration, the inheritance of acquired characters, and many other facts pertaining to inheritance, variation, and development, Darwin elaborated his "provisional hypothesis of Pangenesis" - a developmental theory of heredity. Darwin's Pangenesis had two basic postulates: first, that the cells of the body throw off molecules-gemmules (the embryonic form of our modern genes), which "circulate freely throughout the system"; and second, that these gemmules are not only self-replicating and corpuscular, but also can penetrate other nascent cells and modify their subsequent development. According to Darwin's pangenesis, the formative matter within the pollen of plants, which consists of gemmules, can unite with and modify the partially developed cells of the mother plant. $\mathrm{He}$ believed that "the gemmules derived from the foreign pollen do not become developed merely in contact with pre-existing cells, but actually penetrate the nascent cells of the mother plant. According to this view, the cells of the mother-plant may almost literally be said to be fertilized by the gemmules derived from the foreign pollen" (Darwin, 1868). Unfortunately, Darwin's explanation was totally unknown and ignored by our plant biologists.

Received for publication 31 Dec. 2007. Accepted for publication 28 Jan. 2008.

${ }^{1}$ Current address: Department of Biochemistry, University of Alberta, Edmonton, AB, T6G 2H7, Canada.

${ }^{2}$ To whom reprint requests should be addressed; e-mail ysliu63@yahoo.ca de Vries and Correns, the two chief actors in the founding of genetics, also realized the importance of xenia, but their explanations for this phenomenon are different from Darwin's. They showed that xenia in maize could be explained by double fertilization (Dunn, 1973). Double fertilization may be the explanation of the direct effect of pollen on the seed, but it does not count for the influence on the fruit outside the embryo and endosperm.

Swingle (1928) surmised that there is an analogy to hormone action in the bodies of animals: "The simplest and most probable theory to explain metaxenia is that the embryo or endosperm or both of them secrete hormones, or soluble substances analogous to them, which diffuse out into the tissues of the mother plant that constitute the seed and fruit and there exert a specific effect on these tissues, varying according to the particular male parent used to fecundate the embryo and endosperm." Dag and Mizrahi (2005) suggested that seed number is correlated with fruit size in many crops. They supposed that the developing seeds secrete hormones (mainly auxins) that promote development of the ovary, leading to larger fruit. Although this hormone action hypothesis is widely accepted, it remains unsatisfactory because the parallelism in plants between the metaxenia effects and the characters of the pollen parent suggests that secretions may be initiated by the genes that determine the characters. In addition, Denney (1992) asked a good question: if the embryo secretes hormones affecting maternal tissue, how can the endosperm and the embryo itself not be affected by these same hormones?

Transposons have also been considered as candidates for the root cause of many xenia phenomena. However, transposons only move between chromosomes. They do not "jump" from syngamous tissue to maternal tissue as Denney (1992) pointed out. Kermicle (1978) described the phenomenon of imprinting, in which there is preferential expression of genes depending on whether the genes were inherited from the paternal or the maternal side. Paternal imprinting can clearly affect endosperm development and kernel size in corn, thus explaining certain cases of xenia. Such imprinting, or parent-specific gene expression (PSGE), occurs in higher plants. Although the theory that PSGE solves genetic conflict between mother and father is widely accepted, de Jong and Scott (2007) argued that the conditions for PSGE to evolve are restricted. With respect to seed size, PSGE can only evolve when the developing offspring has a strong effect on its own resource acquisition.

Traditionally, RNA molecules are thought to function within the same cell in which they are generated. Recent evidence, however, reveals that in addition to this conventional role, RNA also acts as a noncell-autonomous signal molecule that travels intercellularly to regulate gene expression in remote target tissues. Kim et al. (2001) demonstrated that endogenous mRNA molecules not only travel between plant cells, but also are capable of causing phenotypic change in developing tissue. Kudo and Harada (2007) also showed that a graft-transmissible RNA from tomato rootstock without any leaves can change leaf morphology of the potato. More interestingly, mRNAs have been reported not only in mammalian spermatozoa, but also in the male gametes of plants. For example, Engel et al. (2003) showed that the sperm cells of Zea mays have a complex complement of mRNAs. It has been suggested Darwin's socalled gemmules could include RNAs, particularly mRNA and small RNAs (Liu, 2006). These reports lead me to assume that, during fertilization, pollen releases mRNAs, which diffuse out into the tissues of the mother plant and there the translocated mRNAs cause changes in size, shape, color, developmental timing, and chemical composition of seeds and fruits, varying according to the particular male parent. This idea is consistent with Darwin's pangenetic explanation.

\section{Literature Cited}

Dag, A. and Y. Mizrahi. 2005. Effect of pollination method on fruit set and fruit characteristics in the vine cactus Selenicereus megalanthus ('yellow pitaya'). J. Hort. Sci. Biotechnol. 80:618-622.

Darwin, C. 1868. The variation of animals and plants under domestication. John Murray, London, UK.

de Jong, T.J. and R.J. Scott. 2007. Parental conflict does not necessarily lead to the evolution of imprinting. Trends Plant Sci. 12:439-443.

Denney, J.O. 1992. Xenia includes metaxenia. HortScience 27:722-727.

Dunn, L.C. 1973. Xenia and the origin of genetics. Proc. Amer. Philos. Soc. 117:105-111.

Engel, M.L., A. Chaboud, C. Dumas, and S.M. Cormick. 2003. Sperm cells of Zea mays have a complex complement of mRNAs. Plant J. 34:697-707.

Kermicle, J.L. 1978. Imprinting of gene action on maize endosperm, p. 357-371. In: Walden, D.B. (ed.). Maize breeding and genetics. Wiley, New York, NY.

Kim, M., W. Canio, S. Kessler, and N. Sinha. 2001. Developmental changes due to long-distance movement of a homebox fusion transcript in tomato. Science 293:287-289.

Kudo, H. and T. Harada. 2007. A graft-transmissible RNA from tomato rootstock changes leaf morphology of potato scion. HortScience 42: 225-226.

Liu, Y.-S. 2006. Response to Till-Bottraud and Gaggiotti: Going back to Darwin's works. Trends Plant Sci. 11:472-473.

Swingle, W.T. 1928. Metaxenia in the date palm-Possibly a hormone action by the embryo or endosperm. J. Hered. 19:257-268. 